\title{
DENTOALVEOLAR SPECIFICS IN CHILDREN WITH CLEFT PALATE DURING PRIMARY OCCLUSION PERIOD
}

\section{Sergei Dmitrienko, Michael Porfiriadis, Dmitry Domenyuk, Gasan Budaychiev}

Congenital malformations are rated among the top urgent medical and social issues, which is due to the high incidence of the pathologies, as well as the severity of morphological and functional changes in newborns. In the structure of congenital malformations, the cleft upper lip, palate and alveolar process rank second, and belong to the worst malformations of the face and the jaws, which leads to significant anatomical, physiological and cosmetic troubles [2]. A reasonable expansion of indications for biometric studies of jaw models and cephalometric measurements through orthodontic treatment given to children with cleft upper lips, palate and alveolar processes would allow not only objective evaluation of the instrumental treatment effectiveness aimed at improving the shape and the dimensions of dental arches, occlusal ratios, yet would also increase significantly the diagnostic value of anthropometric studies, with meaningful outcomes being obtained for dentistry $[1,3,4,5,6]$.

Arm. Identifying the specific dentoalveolar features in children with unilateral cleft alveo-lar process at the primary occlusion period.

Materials and METHODs. The group, which included 37 children aged 4 to 6 with unilateral cleft upper lip and alveolar process, had their facial parameters and dental arches examined. The facial dimensions were measured in two sections, vertically. The nasal area was measured be-tween the glabella points $(\mathrm{g})$ and the subnasale (sn). The gnathic part was taken between the sub-nasal point and the gnathion point (gn). In the event the face width between the zygomatic points (zy-zy) caused no difficulty, then, when measuring the nose width between the most prominent lateral points, the alare (al-al) was measured along both halves of the aesthetic center face line. The measurements allowed assessing the location asymmetry of the nose wings in case of maxillofacial congenital pathologies. A similar measurement method was carried out at biometric examination of jaw stone models. The dental arch width between the second primary molars was taken as the conventional middle line of the upper dental arch. The line was divided into two equal halves and a perpendicular was drawn forward starting from the center.
The width of half-arch at the level of the canines and molars was measured from the conventional midline. This line served a guide for measuring arch depth, and allowed evaluating the interincisal point displacement. The dental arch diagonal dimensions, meanwhile, were measured from the interincisal point to the canines and second primary molars.

RESUlTS ANid DisCussion. The study of the maxillofacial region carried out in the study groups has shown that the vertical facial parameters measured from the g-point to the gn-point were $98.83 \pm 1.82$ $\mathrm{mm}$, the value being below that found in the children's peers who had orthognathic bite, and which was explained by a congenital pathology. The height of the nasal (g-sn) and gnathic (sn-gn) parts was 48.92 $\pm 0.95 \mathrm{~mm}$ and $48.96 \pm 0.86 \mathrm{~mm}$, respectively. The latitudinal facial parameters between the zygomatic points were $109.85 \pm 1.56 \mathrm{~mm}$. If the total width of the external nose was $32.45 \pm 0.32 \mathrm{~mm}$, then the sizes of the left and right sides in children with cleft upper lips and alveolar processes were different. On the cleft side, the external nose width measured from the aesthetic center line, was an average $2.5 \mathrm{~mm}$ above the same measurement on the intact side. The biometric study has shown that the transversal dimensions of the anterior part of the dental arch in children with cleft alveolar processes are most vulnerable to alteration. Notable is the symmetry of the dental arch. The dental arch width measured from the canines to the aesthetic center line, was significantly smaller on the cleft side $(11.49 \pm 0.42 \mathrm{~mm})$, while on the intact side the same parameter was $16.32 \pm 0.25 \mathrm{~mm}$. In total, the intercanine distance did not exceed $30 \mathrm{~mm}$. The anomaly facilitated the alteration in the parameters in the sagittal direction, which was more prominent in the anterior part of the dental arch. And the alterations were expressed equally on both sides. The anterior section pathology was also to be seen in the magnitude of the dental arch total depth. The depth of the anterior part of the dental arch on the cleft side was $6.54 \pm 0.82 \mathrm{~mm}$, while on the intact side it was $6.91 \pm 0.45 \mathrm{~mm}$. It is important to note the discrepancy between the dental arch diagonal dimensions in children with congenital pathology, the dimensions of the anterior dental arch diagonals and the entire dental arch of the primary occlusion. The anterior diagonal on the intact side was $16.52 \pm 0.73 \mathrm{~mm}$, whereas on the cleft side it was significantly smaller $(13.41 \pm 0.54, \mathrm{p} \leq 0.05)$. The dental 
arch diagonal on the cleft and on the opposite sides was $32.34 \pm 0.46$ and $33.56 \pm 0.41 \mathrm{~mm}$, respectively.

Conclusion. The study has revealed anthropometric facial specifics and biometric values of dental arches in children with congenital unilateral cleft upper lip, alveolar process and palate. It was observed that on the cleft upper lip side, the external nose width, measured from the aesthetic center line, exceeded that on the intact side by an average of $2.5 \mathrm{~mm}$. The biometric measurements have shown that the transversal dimensions of the anterior dental arch are most susceptible to alteration. The dental arch width, measured from the canines to the aesthetic center line, was significantly smaller on the cleft side $-11.49 \pm 0.42 \mathrm{~mm}$, while on the intact side the same parameter measured $16.32 \pm 0.25 \mathrm{~mm}$. The entire intercanine distance did not exceed $30 \mathrm{~mm}$. The obtained data can be used in the clinical orthodontics for diagnosing anomalies in the dental arch shape and size, as well as to select the best orthodontic treatment offered to children with congenital unilateral cleft upper lip, alveolar process and palate.

\section{REFERENCES}

1. Dmitrienko S.V., Domenyuk D.A., Vedeshina E.G. Shape individualization in lower dental arches drawn on basic morphometric features // Archiv EuroMedica, 2015. - Vol. 5. - № 1. - P. 11-15.

2. Domenyuk D.A., Vedeshina E.G., Dmitrienko S.V. Dynamics of changes in transverse and frontalretromolar jaw sizes in children throughout the orthodontic treatment stages. Kubanskij nauchnyj medicinskij vestnik. 2016;(3):51-59. (In Russ.) DOI:10.25207/1608-6228-2016-3-51-59.

3. Domenyuk D.A., Shkarin V.V., Porfiriadis M.P., DMitrienko D.S., DMitrienko S.V. Classification of facial types in view of gnathology // Archiv EuroMedica, 2017. - T. 7. - № 1. - C. 8-13.

4. Domenyuk, D.A. Modern classification of dental arches / D.A. Domenyuk, S.V. Dmitrienko // Archiv EuroMedica, 2014. - Vol. 4. - № 2. - P. 14-16.

5. Shkarin V.V., Domenyuk D.A., Porfiriadis M.P., DMitrienko D.S., DMitrienko S.V. Mathematical and graphics simulation for individual shape of maxillary dental arch // Archiv Euro-Medica, 2017. T. 7. - № 1. - C. 60-65.

6. ShKarin V.V., Porfiriadis M.P., DOMENYUK D.A., Dmitrienko D.S., Dmitrienko S.V. Setting reference points for key teeth location in case of abnormal dental arch shape //Archiv EuroMedica. - 2017. - V.7. - № 2. - C. 111-117.

\section{IMPROVING ODONTOMETRIC DIAGNOSTICS AT JAW STONE MODEL EXAMINATION}

\section{Dmitry Domenyuk, Alexander Lepilin, Igor Fomin, Sergei Dmitrienko, Gasan Budaychiev}

Studying the teeth morphology is fundamental for identifying the gender, the race, the variability of the dentoalveolar system under different physique types, as well as the variability of the tooth shape subject to the somatic type $[1,5]$. Biometric investigation of jaw stone models is of applied and practical importance in clinical dental practice. The major dimensions of teeth in people with physiological types of occlusion have been shown for various gnathic and dental arch types $[3,6]$. Notable are researchers' recommendations pointing at the need to employ odontometric data to identify the correspondence between the tooth size and the parameters of the dentoalveolar system and the craniofacial complex as a whole [2, 4]. However, the same odon-tometric parameters are interpreted ambiguously by experts, which makes the research outcomes incomparable.

Arm. Developing a teeth measuring algorithm for evaluating odontometric parameters at studying jaw stone models.

Materials and Methods. The biometric study was performed on jaw stone models obtained from 107 people (aged 20-25) with physiological types of occlusion and a full set of teeth. As the initial size for odontometry, we chose the mesial-distal width of the crowns on the teeth that constitute the dentition. Besides, on the first and second permanent molars we measured the vestibular-lingual diameter of the crown. For this, a conditional midline was applied on the vestibular and lingual surfaces of the teeth, which connected the medial points of the mesial-distal width near the occlusal surface and the clinical dental neck. The diameter was measured between the said lines at the points corresponding to the location of the tooth 